\title{
ANNOUNCEMENT
}

\section{Society for Computers in Psychology \\ Public Domain Software Swap}

At the annual meeting of the Society for Computers in Psychology, some members engaged in a software swap. The listing supplied here contains names and descriptions for software swapped at the meetings, plus a few additions. Individuals interested in any of the listed programs should contact the contributor directly; for disk copies of the program, please send a disk plus $\$ 1$ per vol. to: Cyndi McDaniel, Psychology Department, Northern Kentucky University, Highland Heights, Kentucky 41076.

\section{Vol. 1. Contributor: David Eckerman, University of North Carolina, Chapel Hill}

System: Apple II family, Mountain Hardware Clock in slot 4

Description: Crimestop. As a member of CrimeStoppers International you collect tips about crimes from two informants. The informants sometimes give "old" information. You must discover the schedule of new and old information to maximize your information gathering.

Vol. 2. Contributor: Emory Sadler, North Carolina A\&T, SU

System: Apple II family, ProDOS

Description: Assorted programs, including a model of the DSM-III and a program to create and administer Question/Answer quizzes.

Vol. 3. Contributor: Wayne Norman, Northwestern College

System: Apple II family, game paddles, ThunderClock

Description: Apple Picker (see program). A software package for investigating concurrent schedule matching and multiple schedule behavior contrast. Subjects respond by searching for "apples" in two "orchards." Search responses may be reinforced according to ratio or interval schedules.

Vol. 4. Contributor: Michael Granaas, University of Kansas

System: Apple II family, Pascal

Description: Simple, Applied Text Parsing (see program). A simple text parser for use in a specific research setting.

Vol. 5. Contributor: Bennett Bertenthal, University of Virginia

System: Apple II family, Texas Instruments animation chip

Description: 3-D Graphics Animation (see program). A graphics design program for creating point-light displays of transforming 3-D objects.

Vol. 6. Contributor: Cyndi McDaniel, Northern Kentucky University

System: Apple II family

Description: A disk full of utility programs, including un-delete.

Vol. 7. Contributor: Gary Perlman, Wang Institute, Tyng Rd, Tyngsboro, MA 01879. Contact contributor for copies ( $\$ 20$ for tape and mailing) and information.

System: UNIX, C language

Description: UNIX/STAT, about 20 programs for data manipulation and analysis (documentation available).

Vol. 8. Contributor: Howard Kaplan, Addiction Research Foundation, 33 Russell St., Toronto, Ontario, Canada M5S 2S1. Contact contributor for copies and information.

System: IBM, PC-DOS 2.10, Turbo Pascal

Description: FREDL, general-purpose operant conditioning system to control 8 Skinner boxes, record data on disk, produce cumulative records and other summaries.

Vol. 9. Contributor: Naoyuki Osaka, Department of Psychology, Otemon-Gakuin University, Ibaraki, Osaka 567, Japan. Contact contributor for copies and information.

System: PC9801, PC8801, FM-8, PET/CBM, VIC-20

Description: File transfer programs for NEC's PC-series personal computers and Fujitsu's FM-8 personal computer (telecommunication). The program transfers data to host mainframes (IBM-compatible machines) from personal computer-based terminal emulators. 
Vol, 10. Contributor: Adam Weisman, Kent State University, Kent, $\mathrm{OH}$

System: Apple II

Description: A host of statistical utility programs.

Vol. 11. Contributor: Russel L. Boice, University of Southern Colorado

System: Apple II family

Description: Programs to plot signal-detection values and plotter routines.

Vol. 12. Contributor: Don Overton, Temple University, Philadelphia. Contact contributor for copies and information. System: Apple II with $\mathrm{CP} / \mathrm{M}$ and 80 column card

Description: MBASIC spreadsheet program allowing manipulations of two-dimensional data arrays.

Vol. 13. Contributor: Gerd Stuemer, Hospitalshasse Strasse, 7000 Hamburg 50, West Germany

System: Apple II family

Description: Line-oriented BASIC editor from AppleWriter II or IIe which permits use of labels rather than line numbers.

Vol. 14. Contributor: Brian Watts, New York University, 6 Washington Place, 8th Floor, New York, NY 10003. Additional utilities are available from contributor.

System: Apple II family

Description: Forth $\mathrm{T}+$, a personal variation of FORTH programming language.

Vol. 15. Contributor: Daniel Gould, Behavioral Neurology, EK Shriver Center, 200 Trapelo Road, Waltham, MA 02053. Contact contributor for updates and information.

System: IBM compatible with graphics adaptor

Description: Programs to conduct matching-to-sample experiments using graphic or alphanumeric stimuli. Written in Turbo Pascal.

Vol. 16. Contributor: Suzanne Bousquet, Kean College of New Jersey, Union, NJ 07083. Documentation available from contributor.

System: Apple II family

Description: Programs to demonstrate some concepts in learning and memory.

Vol. 17. Contributor: Dave Landrigan, University of Lowell, Lowell, MA 01854

System: IBM 8088/8086 family

Description: ESIE Expert system (AI), TESTNP test-retest, random number generators, utilities, and more.

Vol. 18. Contributor: Dave Landrigan, University of Lowell, Lowell, MA 01854

System: Bulletin Board (300/1200 baud)

Description: BASA (Mass Psych Assoc) Electronic Bulletin Board (RBBS) and Conferencing System for sharing information, resources, and programs 24 hours a day/7 days a week. DATA-617-491-7999, VOICE-617-491-6223.

Vol. 19. Contributor: Gary Perlman, Wang Institute, Tyng Road, Tyngsboro, MA 01879. Documentation and updates available from contributor.

System: MSDOS

Description: UNIX|Stat 5.1 is a set of data manipulation and analysis programs originally developed with the UNIX philosophy. 